\title{
Analysis of the Quality on English Microlectures of Senior High School from Perspectives of Teaching Philosophy, Second Language Acquisition Mechanism and Education Psychology
}

\author{
Yang Yuqian ${ }^{1}$ \\ ${ }^{1}$ School of Foreign Languages and Literature, Wuhan University, Wuhan, China \\ Correspondence: School of Foreign Languages and Literature, Wuhan University, Wuhan, China.
}

Received: September 20, 2018

doi:10.11114/ijsss.v6i11.3639

\author{
Accepted: October 8, 2018 \\ Available online: October 12, 2018 \\ URL: https://doi.org/10.11114/ijsss.v6i11.3639
}

\begin{abstract}
Concerning the fact that a large amount of teachers have been participated in the microlectures competition, it means the concept of microlectures has been recognized. However, English teachers are devoted to participating in these competitions but fail to put microlectures into practical teaching. Therefore, the focus of this paper is going to answer the following two questions, that is, how to make a good microlecture and how to use it properly. This paper chooses four videos from The Third China's Microlectures Competition to analysis from three aspects: teaching philosophy, second language acquisition mechanism and education psychology. It is found that English teachers from senior high school generally do not understand the concept of microlectures. Generally speaking, teachers are intended to win the award of the competition but fail to put microlectures in the practical teaching. Teachers are inclined to select big topics, untypical teaching materials. What's more, the structure of microlectures isn't complete since some teachers ignore the exercise part. Based on these problems, on the one hand, English teachers should insist on life-long study and apply the latest education technologies into practical teaching. On the other hand, the organization of the whole microlecture should be developed logically. Suggestions are provided with teachers on how to make a make a good microlecture and how to use it properly.
\end{abstract}

Keywords: teaching videos, microlectures, teaching procedures, teaching analysis

\section{Introduction}

With the popularity of microlectures, Schools and the relevant departments attach high importance to the promotion of microlectures in China. Therefore, to encourage teachers to apply microlectures into practical teaching, the National Microlectures Competition has been held every year since 2014 by Education Management Information center which is charged by Ministry of Education of China to attract teachers' attention. It's worth noting that the Competition is directly targeted at teachers from basic education stage. Every year teachers from different provinces of China take active part in the National Microlectures Competition and upload their videos in the website. Therefore, we can have easy access to these videos and take a close look at these videos. Concerning the fact that a large amount of teachers have been participated in the microlectures competition, it means the concept of microlectures has been recognized. However, the microlectures fail to be put into practical teaching. Therefore, the focus of this paper is going to answer the following two questions, that is, how to make a good microlecture and how to use it properly. Several typical microlectures are chosen in order to find the potential problems in the microlectures, thus providing practical advice on how to make microlectures.

\section{Researches on Microlectures}

The rise of information technology has promoted the birth of microlectures. Professor LeRoy A. McGrew (1993) of University of Northern Iowa proposed 60-Second Course, that is, the microlecture. Concerning the fact that the organic chemistry course is boring and complex, non-organic chemistry majors have to spend most of their time and energy in the course. With the help of 60-Second Course, learners who are eager to learn organic chemistry have easy access to professional courses in a novel way. Generally speaking, 60-second course consists of three parts, that is, general introduction, explanation, and special examples combined with the chemistry of life (Mcgrew, 1993).

In the 1995, T. P. Kee from Napier University put forward the concept of "The One Minute Lecture". In the end of 20th, 
the update speed of knowledge has become so rapid that people have to master new knowledge comprehensively in such a short time. Under such circumstance, T. P. Kee guided students to design one-minute lecture with tight structure and wonderful design so that core concepts can be conveyed (T. P. Kee, 1995).

American David Penrose developed the microlectures for San Juan College. As far as Penrose is concerned, the microlectures are of great benefit to motivate students' interest and encourage active learning. The microlectures can prime students to learn from completing the assignments that follow the microlectures (David Shieh, 2009). For one thing, microlectures can be an introduction to encourage students to dig deeper into the subject. For another, it's more convenient to preview and review a microlecture which just lasts about 10 minutes at most. Although 10 minutes can't illustrate a problem comprehensively and thoroughly, the microlectures can be conducive to helping students become responsible for their study (Dawn Sweet, 2014). Nowadays, the microlectures have combined with flipped classroom(Jonathan Bergmann \& Aaron Sams, 2012). Wen Chuanxue and Zhang Junfei(2015) proposed a novel way of micro-learning with the support of microlectures through PC terminals and smartphones. Having easy access to microlectures, students can see microlectures everywhere at any time to realize the mobile learning and ubiquitous learning. However, Libby V. Morris(2009) compared the traditional lecture with the microlecture and gave his reflections on the microlecture

Furthermore, the microlecture platforms or websites are developed rapidly in the past 20 years. Popular all over the world, Khan Academy and TED attracted widespread attention. The reason why the popularity of Khan Academy is that KA realize the personalized education(Cargile \& Harkness, 2015). In fact, the nature of the microlecture is "old things in new ways" because the teaching contents actually don't change basically(Sandeen, 2013). And the Khan Academy also applies the microlectures in the teaching. Generally speaking, a course consists of a series of microlectures.

Teachers at home and abroad attempt to employ microlectures in their teaching, but most of them focus on the form of microlecture. For example, teachers combine flipped classroom, MOOC with microlectures but fail to pay attention to the quality of microlectures itself. In addition, compared with the rapid development of microlectures abroad, few microlectures in China are adopted in practical teaching. The thesis tries to discovery the potential problems of the current microlectures, thus providing constructive suggestions on the promotion of microlectures in the practical teaching.

\section{Theoretical Foundation}

Targeted at the whole learning process, the thesis attempts to analyze the English microlectures from three aspects expecting to provide constructive advice with English teachers.

First of all, teachers have to consider what should be embodied in the lecture. Progressivism, as a kind of teaching belief, guides teachers to design the whole class scientifically. Coordinated with the New English Curriculum Standards, Progressivism puts equal attention to the knowledge and capabilities, process and methods, emotions, attitudes and values. Especially, there are about 150 videos in the Third China's Microlectures Competition concentrating on grammar and lexicon, and the emotion aspect has often been ignored in English teaching. Actually, the current microlectures draw attention to knowledge aspect generally, thus overlooking the humanity aspect of English. Dewey(1959, 1997) advocated child-centered, activity-centered and school as an embryonic society. That means students should be treated as a whole-being. Under the guidance of Progressivism, teachers should draw attention to the comprehensive development of students. The responsibility of an English teacher is not only to convey linguistic knowledge but also to care about students' learning feelings and emotions. In other words, students are expected to have access to the instrumental and humanity aspects of English. Therefore, both the linguistic knowledge and the humanity aspects should be embodied in the microlectures.

Next, the paper is going to discuss how to design the microlecture specifically. Generally speaking, the microlecture is classified into three parts, the lead-in part, the middle part, the exercise part.

In fact, the microlecture can be seen as a learning process in which students are exposed to the new knowledge, try to understand it, and then consolidate it. The meaningful learning theory(Ausubel, 1963) advanced a close relationship should be established between the new knowledge and the previous knowledge. Such a relationship can narrow the gap between the knowledge and practice. Actually, every step taken by teachers is supposed to be linked with each other from the beginning to the end. Teachers have to identify different kinds of learning types according to the ideas of superlative, subordinate, and combinatorial learning. However, despite the fact that Ausubel had stated the three types of learning, it's not easy for English teachers to classify the new knowledge into the specific type of learning mentioned above since the linguistic knowledge is sometimes scattered everywhere. Thanks to the Input Hypothesis, the mentioned problem can be solved within the linguistic field. According to the comprehensible input, the new knowledge can be understood by students and they still feel a little challenge(Krashen, 1985). That means students are familiar with most of words or grammatical points and they can understand the sentence basically in virtue of semantic or syntactic 
relations. In terms of English, the meaningful relationship is embodied in the semantic or syntactic aspects. Consequently, when it comes to the lead-in part of the microlecture, teachers can use familiar topics to introduce new lexicon or grammar. On the other hand, teachers can establish the relations by familiar topics or contents. English teachers are also expected to adopt the topics from English textbooks so that students can step into the learning state quickly.

After the lead-in part, teachers begin to illustrate the new knowledge carefully so that students can understand it thoroughly. This part is involved in the learning mechanism. In general, the demonstration process should be based on the previous part. In other words, the latter part has a meaningful relationship with the former part in terms of semantic, syntactic, logical aspects. Besides, examples are often used when teachers demonstrate an important point, especially grammar. It's obvious that the exemplifying belongs to the subordinate learning. When teachers capitalize on examples to explain what they are going to illustrate, they had better provide enough examples to reflect the knowledge point comprehensively and thoroughly. For example, if teachers attempt to demonstrate the subject-predicate agreement, students are expected to have access to every type of the subject-predicate agreement and variants of different types.

In the last part, having finished the whole demonstration, teachers usually were likely to design an exercise part to consolidate what students have learned just now. According to the output hypothesis (Krashen, 1985), different forms of exercises or activities can check the learning progress of the students. Swain (1995) demonstrated three functions of output in second language learning, that is, the noticing/ triggering function, the hypothesis testing function and the metalinguistic reflective function. The noticing function refers to the fact that output makes learners notice the flaws. Evidence showed that learners would modify their output according to clarification requests or confirmation checks. It was found that one third students made improvements in semantic or syntactic aspects by means of negative evidence(Pica, et al., 1989).

However, with answers attached in the following part, students can overlook the microlecture completely on the ground that it doesn't influence the normal learning progress. In other words, without the overt monitoring, students tend to be lazy so that the microlecture hasn't been put into practical teaching and embedded into the English class properly. Lacking of motivation, students are unwilling to watch extra teaching videos. Therefore, the microlecture, on the one hand, has to be linked with the English class in terms of structure. On the other hand, the grammar exercises are not the only way to check the output or help students review. According to the output hypothesis, the various output ways can stimulate students to reflect the whole learning process, correct the misunderstandings, or even improve the English skills. What's more, as Progressivism requires, students are expected to discover the linguistic law or participate in the knowledge application. To satisfy this kind of need, the semi-structured Micro video is advocated to establish an overt relation between English class and the microlecture in virtue of monitoring mechanism, especially teachers' orders. Rather than give answer directly, the so-called semi-structured microlecture attempts to replace the traditional grammar exercises with the open questions or homework.

\section{The General Description of Microlectures}

The paper attempts to choose the microlectures from the Third China's microlectures Competition on the official website. As the official website, the Chinse Microlecture Website is the official website for the microlecture competition of basic education phase, in which also attracts a large amount of teachers from basic education phase to participate. In other words, the microlectures from the official website can be more representative and stand up the whole quality of microlectures made by English teachers from the basic education phase. Therefore, this paper chooses the English microlectures of senior high school as the whole research population. By analysis, 4 microlectures are chosen as the sample to analysis in detail.

Statistically, there are 270 English microlectures of senior high school on the website. Having watched all of the videos, this paper attempts to divide the 270 English microlectures into 3 types according to the contents of the microlectures, that is, videos redeveloped from texts, grammar, lexicon, and techniques. The first type refers to the videos whose contents are from the texts of English textbooks. It's obvious that the videos about grammar and lexicon mainly elaborate tense, syntax, morphology, etc. The techniques chiefly introduce the practical skills, such as writing skills, oral English skills, reading skills and so on. Influenced by College Entrance Examination in China, microlectures are also targeted at the special test types, such as the cloze test, reading comprehension, and writing.

From the table below, Statistically, 68 microlectures are adapted from the English textbooks most of which are published by People's Education Press, Foreign Language Teaching and Research Press, Oxford University Press, Beijing Normal University Press. In actuality, about 25.18\% microlectures are matched with textbooks, among which mainly focus on the textbook published by People's Education Press. The reason why the PEP edition is popular with English teachers in making microlectures is that most of schools all over the China use this kind of textbooks. And it shows that 54 videos are test-oriented aiming at improving students' test-taking skills. 
Adding up to 148, the microlectures about grammar and lexicon elaborate the syntactical knowledge and the usages of important words carefully, such as appositive clause, attributive clause, inverted sentences, and the usages of "until" etc. The number of videos in this category also shows indirectly how important the aspect.

Even though all microlectures, indirectly or directly, are involved in listening, reading, speaking and writing aspects, few videos are specially designed to improve students' listening skills. By contrast, most of microlectures concentrate on grammar, which means it's not enough for English teachers to study textbooks. What's more, the purpose of these microlectures is to expect students to fill the grammar blanks correctly. Therefore, grammar exercises are usually designed in the microlectures and the right answers will be attached at the end of the videos. What's worse, some English teachers are likely to present the new knowledge with only one example.

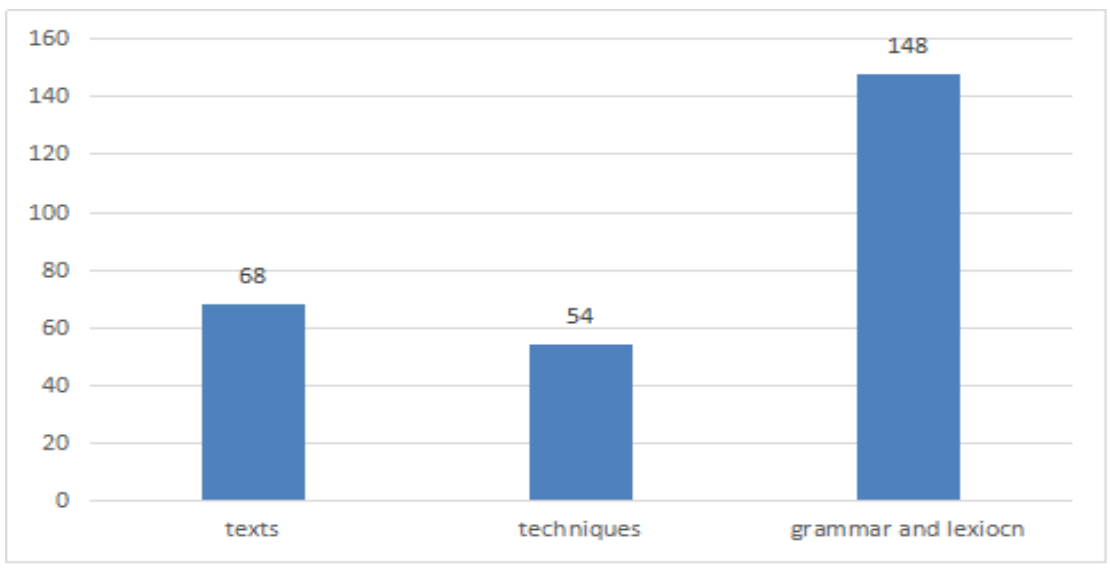

Figure 1. The Category of Microlecture

\section{Methodology}

In order to discover the problems of microlectures and put forward practical suggestions for teachers, the paper attempts to take a qualitative approach to analyze the four videos from teaching philosophy, second language acquisition mechanism and education psychology. The four videos selected randomly from 270 microlectures stand for the three mentioned aspects respectively, that is, texts, grammar and lexicon, and techniques.

\subsection{Research Questions}

Based on the previous illustration, the thesis mainly analyzes the microlectures to discover the problems in these videos. Therefore, the research questions of this thesis focus on the two following questions:

1) How do English teachers design the microlecture?

2) How do teachers and students use the microlecture?

It's worth noting that the "design" in the first question actually means "redevelop" in the thesis. Specifically, based on the theoretical framework, the author attempts to analyze the microlectures which mainly include lead-in part, the main illustration part, and the exercise part, thus concluding the problems. And then the author attempts to redevelop the teaching contents according to the theoretical framework. According to the learning process, three kinds of theories are chosen to analyze the microlectures, thus discovering the problems and contributing constructive suggestions.

\subsection{The Selection of the Microlectures}

With so many microlectures available on the China Microlectures Competition Website, the thesis selects four videos to carry out the detailed study, hoping to discover the problems in making microlectures. According to the general description of microlectures, the paper chooses four videos which are classified into three types, that is, texts, grammar and lexicon, and techniques.

The first type is videos which mainly illustrate the articles from the textbooks of students. Concerning the fact that textbooks published by People's Education Press are widely used in China and all students will study compulsory books at least, this paper chooses one video randomly whose content is matched with compulsory book 4.

Besides, considering the fact that the grammar and lexicon are the focus of English teaching in the senior high school phase, two microlectures are chosen which mainly demonstrate grammar and lexicon respectively. In addition, there are microlectures introducing special techniques, such as the writing skills, reading skills. So the thesis chooses a microlecture demonstrating writing skills since writing is of great importance in English learning. 


\subsection{The Analysis of Typical Microlectures}

\subsubsection{Videos Redeveloped From Texts}

Entitled Body Language, the microlecture is matched with the textbook published by People's Education Press. Starting from a picture of Mr. Bean, the microlecture catches up the typical features of him. To put it simply, Mr. Bean, as a comedian, usually express himself by body language. Though he never talks with people by means of speech, people still can understand what he tries to express. On the one hand, Mr. Bean is popular among students due to his humorous acting style so that students are interested in the following materials. On the other hand, the topic is closely related with Mr. Bean whose body language is often used and familiar to everyone. The lead-in part is directly targeted at the topic, thus saving time to the following part.

The following microlecture chooses popular emoji packages which express various feelings, such as happy, sad, disappointed, angry, etc. Showing familiar emoji pictures, the microlecture requires students to guess the meaning of these emoji packages. Furthermore, some commonly used postures are also listed in the microlecture. Therefore, guiding students to observe these pictures, the teacher attempts to conclude the typical features of body language compared with the language we speak. And there is an exercise about the definition of body language requiring students to fill in the blanks by observation and thinking. Basically, designing the teaching procedures carefully, the teacher focuses on the thinking process and guide students to observe, think, and sum up the conclusion. At last, the teacher checks whether the students have understood the former part or not by asking students to fill in the blanks. From emoji to human facial expressions, the teacher guides students to experience the body language used in their daily life. Until now, the teacher insists that the teaching should lay emphasis on how to think and take learners into consideration when he designs the whole class. These all have been advocated by Progressivists. In particular, the previous part is involved in the essential knowledge from the textbook while the following part requires students to think deeply by a question. The question mainly discusses whether the same body language conveys the same meaning in different countries or not. For example, French kiss each other when they meet while Chinese shake hands. While nodding the head means "No" in Indian and Greece, it stands for "Yes" in most societies. Actually, concerning the fact that the question is involved in cross-culture communication, it's more difficult to make a distinction among these gestures just by picture descriptions. The question really kills two birds with one stone. On the one hand, the students are guided to think deeply, which makes the question a little challenging. On the other hand, the teacher introduces some gestures embodying different meanings in different countries to students, which reminds students of behaving themselves in speech and body language to avoid misunderstandings.

Surprisingly, there is a song requiring students' cooperation at the end of the video. For example, students must clap their hands when they hear "if you are happy and you know it, clap your hands". It seems that the song teaches students to recognize their main organs which have nothing to do with body language. According to the meaningful learning theory, only when the materials are related with one another can they be absorbed by students. Now that the song has no relation with body language, the teacher can cut this part off. After all, the unrelated activities or teaching procedures may distract students' attention. At last, there is an exercise part that requires students to write a composition which describes the commonly used body language and explains the meanings. In actuality, it's the exercise part that makes the microlecture more compatible with the normal teaching. Otherwise, just like other online resources, these microlectures are unlikely to be used by students or teachers. To be honest, it's praiseworthy for teachers to stimulate output by dint of microlectures. However, efforts should be made to monitor students to finish the homework carefully. If not, the homework has no impact on learning.

\subsubsection{Grammar and Lexicon}

\section{1) Full Inversion}

Concerning the fact that there are a lot of microlectures demonstrating grammar, the thesis chooses the microlecture which mainly demonstrates the full inversion to analyze. The microlecture attempts to make a summary about the full inversion. Like the other microlectures, it always follows the patterns: definition, rules, and grammar exercises. Compared with the normal order of sentences, the teacher employs simple examples to illustrate which part is inverted. In case those learners still feel confused about the concept of full inversion, the teacher takes the sentence pattern "there be" as an example to further elaborate the full inversion. By showing the original sentence pattern of "there be" without inversion, the teacher reviews the definition of full inversion again. The teacher uses the same sentence to compare the normal order sentence with the inverted one, which is conducive to gaining deep understandings. As the comparative organizer advocates, the teacher uses one of the basic sentence types to explain why these new sentences are called inverted sentences. By comparison, a classic example is used to relate the prior knowledge with the new knowledge.

The video which illustrates the full inversion has a good beginning since the teacher employs "there be" pattern to 
arouse students' interest in thinking about the following part. Unfortunately, the teacher tells students all the linguistic rules at one time. It's horrible to read and remember so many linguistics rules when students first learn new knowledge without understanding. What's worse, since students have no idea of these rules, they can't understand thoroughly in a short time. Instead of presenting all linguistic rules together, the teacher should demonstrate them one by one and organize the whole microlecture hierarchically and orderly. Although the teacher divides full inversion into four groups according to different adverbs, such as directional adverbs, temporal adverbs, positional adverbs, the following examples fail to demonstrate these rules clearly and mix them up. Presenting the examples on the screen, the teacher doesn't make full use of examples because he fails to illustrate examples combined with linguistic rules.

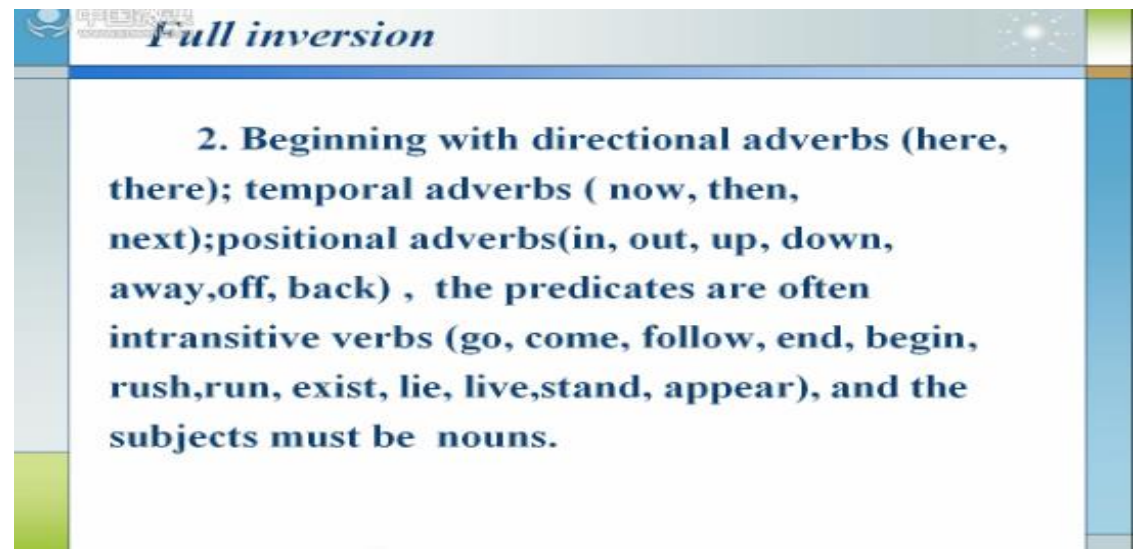

Figure 2. An Example from Full Inversion

Besides, it's not enough for teachers to provide one or two examples with students. If the topic contains plenty of knowledge points, teachers have to cover the new knowledge comprehensively within 10 minutes. Apparently, teachers are short of time to illustrate new knowledge thoroughly. However, only when students are exposed to many authentic English examples can they use English naturally according to the input hypothesis. Therefore, it's proper for teachers to choose a small topic to organize the microlectures orderly and supplement enough examples with students.

In general, there are a lot of grammar exercises at the end of the microlecture. The teacher will illustrate exercises in detail and give the right answer finally. If the microlectures follow such a pattern, teachers will never know the students' learning problems. Instead of being given answers directly, students are asked to finish grammar exercises by themselves and tell teachers reasons why they choose the choice. On the one hand, students can really check their learning progress by exercises, and discover their problems timely during the learning process. On the other hand, the teacher will know students' learning troubles so as to explain them together in the class.

It's worth mentioning that the oral English of the teacher is not satisfying owing to the pronunciation. It's true that a lot of English teachers themselves are not good at oral English and easily influenced by their dialects. It's certain that English teachers should pay attention to pronunciation, accent, intonation, etc. Although teachers are equipped with rich knowledge compared with students, they still should insist on learning and improve themselves for a whole life. To solve the problem for the time being now, English teachers perhaps can be in close tandem with one another and take responsibility for one or two parts of the microlectures.

\section{2) Synonym Comparison}

The video belongs to the typical English lecture which distinguishes the synonyms. Owing to the Chinese translation equivalents, students often mix up the three words. At first, teachers describe the hottest news that an earthquake happened in the Jiu Zhai Vally. Unlike math, chemistry, physics, and so on, the linguistic knowledge is often fragmentary so that no special logical relations can be found. Here, the specialty of language teaching should be considered fully. After all, not all the linguistic knowledge can be classified as logic relationship clearly, especially the lexicon. Fortunately, the comprehensible input proposed by Krashen can also achieve the similar effect which reminds students of the previous knowledge and makes students understand the new lexicon at the same time. As a consequence, the semantic or syntactic relations can relate the new lexicon with the familiar lexicon.

When the teacher demonstrates the differences of the three words, the teacher clarifies the usage of every word or phrase respectively. However, the teacher fails to identify why students can't use these words correctly. It's worth noting that students basically know these words and they have already mastered some usages of every word. What makes students confused is how to describe the happening of the event. Therefore, the teacher should make a comparison 
among three words in the same level in which these words share the similar meaning, thus concluding the differences. In the specific teaching process, how to teach depends on the previous knowledge. Most importantly, targeted at the students' learning troubles directly, the teacher should be clear about reasons why students feel confused and which part they tend to mix it up.

Unfortunately, there is lack of an exercise part to check whether students have watched the video, or they have mastered the usages or not. Generally speaking, the teacher can delete the answer attached in the video to make students fill in the blanks. Besides, students can be guided to find more examples which include the three words. Students can tell reasons why the word is used in these sentences.

\subsubsection{Techniques}

There are some microlectures which are mainly introducing skills about how to write a composition, finish a reading comprehension, or a cloze test. Due to the fact that the videos about reading comprehension, cloze, or memorization of lexicon are similar to the previous category and need to reflect the previous knowledge, such as grammar and lexicon, this part chooses the writing skills as the focus to analyze. After all, writing is of significant importance to English learning.

Intended to improve writing skills, the microlecture focuses on polishing up English expressions. A common problem often encountered by EFL learners is how to narrow the gap between what they have learned and what they can write. The microlecture starts with such a puzzling question that it can attract students' attention easily. Unlike other microlectures, the teacher puts forward one of students' learning troubles which are inclined to solve students' problems. It signifies that teachers have to know about their students comprehensively, including strong points and weak points, especially learning difficulties. As the Progressivist advocates, student-centered microlectures should address students' learning difficulties when teachers prepare for the microlectures or design the specific teaching procedures. To put it simply, students' learning feedback should be the focus of the whole microlecture. According to the meaningful learning theory, what the teacher is going to demonstrate should be related with students' prior knowledge, thus the new knowledge can be embedded into students' whole knowledge structure. Before teachers begin to prepare for the microlectures, they must classify the learning relationship between the new microlecture and the prior knowledge, such as superlative learning, combinatorial learning, etc. Obviously, writing belonging to the comprehensive skill, the video is a typical class requiring students to practice based on what they have learned. The video sheds lights on how to introduce the topic of the microlecture according to students' learning difficulties.

All of examples in the microlecture are from students' compositions. Making comments on these examples, the teacher takes place of these words with other words or phrases without changing meaning. Targeted at the phenomenon that students fail to use a wide range of words, phrases and varied syntactic structures, the teacher employs the common words, phrases respectively to illustrate how to polish up English expressions. For example, the word "important" is often used in students' compositions. The teachers replace the word "important" with the verb phrases "attach high importance to" or "of great importance". Due to the fact that students are familiar with examples, it's convenient for students to gain deep understandings of syntactic structures and meanings. When it comes to the syntactic level, the teacher fails to modify the sentence structure. Like the words or phrases, the teacher employs commonly used sentence patterns to replace the original simple words or phrases. It's a pity that the teacher isn't concerned with reorganizing the sentence structures. For example, the teacher replaces "yes" with the sentence pattern "there is no doubt that". And later, with the same method discussed above, the teacher modifies a composition by dint of synonymous substitution.

Finally, it's likely that the teacher thinks that there is no need to arrange exercises on the ground that he just spends the last several minutes in illustrating the writing skills. But it's not the same thing for students to write a composition according to the skills mentioned in the video. Therefore, such kind of opportunity should be available to students to examine their learning progress timely. Now that the teacher makes full use of students' compositions, students can also be guided to polish up their writings according to techniques provided by the video. By doing so, students can realize their problems and be stimulated to improving their compositions. There is no better way than modifying their compositions to consolidate these techniques.

\section{Results Discussion}

The thesis attempts to analyze the selected microlectures from the teaching philosophy, educational psychology, second language acquisition aspects. Combined with the research questions, the thesis attempts to discuss the two aspects, that is, how to design the microlecture, how to use the microlecture.

For the first research question, some problems are discovered during the process of analysis. Actually, it shows that teachers fail to participate in making microlectures actively. Most microlectures always follow the pattern "definition-exemplification-exercise" which concentrates on addressing grammar knowledge. For a long time, English 
teachers illustrate the articles from textbooks in a traditional way which employs the cognitive approach to demonstrate grammar points one by one. Obviously, the text can be designed as a listening class, a reading class, or an oral English class if English teachers are good at designing teaching procedures. Nowadays, thanks to microlectures, teachers can outline the text and guide students to seek detailed information. Or they introduce background information to students in case students are totally unfamiliar with the topic. Honestly speaking, the reason why English teachers are inclined to make microlectures about grammar is that teachers fail to study textbooks thoroughly. Therefore, English teachers don't recognize the deep aspects of textbooks which are used to train students to improve linguistic knowledge and language skills but not to think creatively and critically. That's why so many microlectures pay more attention to basic linguistic knowledge and no more further. English teachers attach high importance to language skills and linguistic knowledge while they tend to overlook the humanity aspects of English and neglect students' emotions, attitudes, and values. Therefore, from the perspective of Progressivism, a microlecture should be concerned about the following aspects, that is, knowledge and capabilities, the learning process and the humanity of English, and the emotions, attitudes, and values.

Specifically, English teachers usually choose a big topic so that they have no enough time to exemplify the details because of only 5-10 minutes of the microlectures. For example, there are a lot of microlectures which mainly demonstrate the attributive clause. It's obvious that a microlecture can't illustrate the attributive clause comprehensively. Therefore, the time constrains teachers use only one example to explain the linguistic knowledge sometimes because of the limited time. As the Krashen puts it, only when students are exposed to the target language environment as much as possible can they acquire the language naturally and quickly. Consequently, it's not enough for students to use new knowledge flexibly by relying on only one example. To put it simply, microlectures can make students notice the important points by means of font color, arrow, font size, or even visualization, etc. When teachers demonstrate new knowledge, they should underline the important points explicitly, thus attracting students' attention to it. As is mentioned before, visualization can be strongly recommended to simplify the linguistic rules.

It's worth noting that the microlectures are used to illustrate a much smaller language point thoroughly, including the short video, a few exercises, and so on. The last exercises are adopted by teachers to help students examine their learning effects and progress. Unfortunately, even though there are only a few microlectures containing exercises, these exercises, in the form of test questions, are closely related with grammar. And teachers are also inclined to provide students with answers at last. It seems that the microlecture has no big impact on students if they never watch it because teachers will never know if students don't take serious attitudes towards the video. As a consequence, just like other online resources, microlectures tend to be laid aside. Therefore, the thesis advocates the concept of the semi-structured microlecture video which means the microlecture is complete in terms of teaching contents as long as students finish these exercises or activities carefully. For instance, the last microlectures discussed above can ask students to modify their own compositions after they watch the microlecture. It's true that there is no enough time for students to do exercises or activities. Students are required to finish the exercises during the free time and show their results in the class. Combined with flipped-classroom study, such exercises avoid the shortcomings of test questions and highlight performance. It's certain that teachers have to play a crucial role in monitoring students to finish the exercise part.

Moreover, some teachers fail to choose typical materials to help student understand. Due to the fact that teachers have, at most, 10 minutes to elaborate the knowledge points, typical examples must be available to students so that they can master linguistic rules or phenomena directly. From microlectures discussed above, if teachers fail to select typical examples, students can't follow the teaching tempo probably because it's impossible for students to have a face-to-face talk with their teachers in order to solve their puzzles. And students may feel reluctant to reach the conclusion so that they cannot understand the lecture thoroughly, let alone apply new knowledge points flexibly. The selection of untypical examples also means teachers are unfamiliar with the thinking habits or cognitive capabilities of students. Knowing about students well, they have to make an assumption about the possible reaction of students when teachers prepare for the microlectures. After all, students don't think the same way as teachers do because of differences of knowledge structure, experience, etc.

As the New Standard Curriculum requires, a lecture should embody the knowledge and capability, process and methods of learning, emotional attitudes and values. Most microlectures fail to realize the third aspect of the requirements. Under the great pressure of College Entrance Examination, English teachers, on the one hand, focus only on linguistic knowledge which is going to be tested in the test. On the other hand, since teachers don't study textbooks carefully, it's a pity that teachers always hold an opinion that grammar is the only priority of English teaching in senior high school phase. Generally speaking, when students are learning some knowledge points, their thinking qualities can also be shaped at the same time. English teaching should make full use of textbooks to stimulate students to think critically and creatively, thus nurturing their thinking qualities.

Moreover, there are irrelevant parts appearing in the microlectures. The so-called irrelevant parts are the teaching 
procedures which have nothing to do with the topic of the microlecture. In general, this kind of microlecture tends to have two problems. One is that the teacher designs the superficially-related teaching procedures which are, essentially, unrelated with the topic. For example, the English teachers design an activity in the selected microlecture named body language. This activity mainly introduces the main body parts, organs, which obviously have no relation with body language. However, according to the meaningful learning theory, the different parts should be linked with each other. If the English teachers fail to do so, students will also have difficulty in understanding these knowledge points. For example, when teachers attempt to demonstrate the body language whose different postures, gestures can also convey information, it's unrelated with how to recognize body parts. For instance, the teacher lists the two methods of diversifying writing skills, that is, synonymous substitution and syntactic structure adjustment. However, students have no chance to see examples involved in syntactic structure adjustments. The teacher still employs commonly-used clauses to replace the original words or phrases. Similar with synonymous substitution, the method doesn't instruct students in adjusting their sentence structures. Embedded in normal teaching procedures, these unrelated teaching materials or activities may take up time and disturb students' learning progress. According to the meaningful learning theory, it doesn't only mean the lead-in part should be closely linked with students' previous knowledge, but also the whole teaching contents should develop logically and be organized orderly.

As for the second question, how to use the microlecture is of great importance because the microlectures fail to be embedded into the practical teaching fully. During the analysis, most microlectures have the exercise part and the answer will be attached in the videos. Once the students know the answer, they may be unwilling to the watch the microlecture. Therefore, the microlecture may fail to influence the student's learning process. In order to solve the problem, semi-structured microlectures are advocated in this thesis. Actually, the so-called "semi-structured" means English teachers, on the one hand, do not give the answers directly in the videos. In other words, English teachers can tell students to finish the exercise part ahead of time, and then tell students the answers in the class. On the other hand, English teachers are advised to design the open questions in the microlectures. For example, English teachers can ask students to find attributive clauses in the textbooks, and then ask students to discover the linguistic laws from these examples. Only in this way can the microlectures be embedded into the class teaching. When students realize English teachers will check their exercises, they have the motivation to watch the video and finish the exercises. Therefore, the traditional microlectures lack of relations between students and teachers. By the semi-structured microlectures, English teachers can monitor students' progress and performance.

\section{Conclusion}

The paper attempts to analyze the selective videos from the theoretical framework, thus some problems are discovered. From the problems mentioned above, we try to give several suggestions.

Firstly, the idea of life-long study should be advocated among teachers. It's obvious that the implementation of the microlecture requires the support of technology. To master how to make microlectures, teachers should welcome new technologies to enhance the learning process instead of resisting. Relevant resources, training opportunities are expected to be available to teachers under the support of related departments, schools. Actually, the making of microlecture is easy to operate, thus hoping teachers are willing to learn and apply it to English teaching. For another, it still requires teachers to study textbooks deeply even though they have been familiar with textbooks. Studying textbooks here refers to the discovery of deep aspects of textbooks, such as emotional attitudes and values, basic linguistic knowledge. In addition, teachers should be aware of the concept of microlecture. Due to time limits, English teachers should be careful about the selection of topics and teaching materials. English teachers had better not choose too big topic when they attempt to make a microlecture because the microlecture limits the whole lecture within 10 minutes. It's wise for teachers to select a relatively small topic or divide a large topic into several microlectures.

Secondly, the organization of the whole microlecture should be developed logically. On the one hand, the lead-in part should take account of students' backgrounds, knowledge or experience so that they are willing to accept new knowledge. What's more, the teaching process still needs to keep to the "from-simple-to complex" principle. There is no doubt that irrelevant parts should be removed from the microlectures to make the whole video organized orderly and logically.

To know about the learning process carefully, the thesis conducts a deep study on the language input and output. With the help of meaningful learning theory, the thesis discusses how students treat the relationship between new knowledge and prior knowledge. Under the guidance of Progressivism, the thesis tries to analyze microlectures carefully in order to discover problems in making or designing the microlectures. By doing so, the thesis expects people involved to attach high importance to the whole learning process. Targeted at the mentioned problems, suggestions are available at the end of the thesis.

All in all, the thesis gains inspirations from the teaching philosophy, second language acquisition mechanism, and 
educational psychology aspects. Thanks to these theories, four English microlectures are analyzed from the pedagogy aspect to discover the potential problems in making microlectures. Unfortunately, the thesis fails to conduct an empirical study to support the research results. Therefore, efforts are expected to make in the future teaching. In actuality, English teachers must change the traditional teaching ideas and be brave to try new things.

\section{Acknowledgements}

My sincere thanks go to Professor Wu Xinhua and Professor Liu SiPing whose professional suggestions enlightened me when I prepare for the thesis. Besides, my heartfelt thanks also go to all my teachers and friends in Wuhan University whose generous helps encourage me to go on for further study.

\section{References}

Hewett, F. M. (1963). The psychology of meaningful verbal learning. California medicine, 99(6), 434.

Bergmann, J., \& Sams, A. (2012). Flip your classroom: Reach every student in every class every day. International society for technology in education. https://doi.org/10.1111/teth.12165

Dewey, J. (1959). The school and society. University of Chicago Press.

Dewey J. (1997). Democracy and education: An introduction to the philosophy of education. New York: The Free Press.

Kee, T. P. (1995). The one minute lecture. EDUCATION IN CHEMISTRY-LONDON-, 32(4), 100-100.

Krashen, S. D. (1985). The input Hypothesis: Issues and Implications. Addison-Wesley Longman Ltd. https://doi.org/10.2307/414800

Krashen, S. D. (1985). Comprehensible Output. System, 26, 175-182.

McGrew, L. A. (1993). A 60-second course in organic chemistry. Journal of chemical education, 70(7), 543. https://doi.org/10.1021/ed070p543

Morris, L. V. (2009). Little lectures? Innovative Higher Education, 34(2), 67-68.

Pica, T., \& Holliday, L. (1989). Comprehensible Output as an Outcome of Linguistic Demands on the Learner. Studies in Second Language Acquisition, 11(1), 63-90. https://doi.org/10.1017/s027226310000783x

Shieh, D. (2009). These lectures are gone in 60 seconds. The Chronicle of Higher Education, 6.

Sweet, D. (2014). Microlectures in a flipped classroom: Application, creation and resources. Mid-Western Educational Researcher, 26(1), 52-59.

Sandeen, C. (2013). Integrating MOOCs into traditional higher education: The emerging "MOOC 3.0" era. Change. The magazine of higher learning, 45(6), 34-39. https://doi.org/10.1080/00091383.2013.842103

Wen, C., \& Zhang, J. (2015). Design of a microlecture mobile learning system based on smartphone and web platforms. IEEE Transactions on Education, 58(3), 203-207. https://doi.org/10.1109/te.2014.2363627

\section{Copyrights}

Copyright for this article is retained by the author(s), with first publication rights granted to the journal.

This is an open-access article distributed under the terms and conditions of the Creative Commons Attribution license which permits unrestricted use, distribution, and reproduction in any medium, provided the original work is properly cited. 